\title{
Comparison of Quality of Life before and after pancreaticoduodenectomy: a prospective study
}

Maria Arvaniti ${ }^{1}$, Nikolaos Danias ${ }^{2}$, Michael Igoumenidis $^{3}$, Vassilios Smyrniotis ${ }^{4}$, Andreas Tsounis ${ }^{5}$, Pavlos Sarafis ${ }^{6}$

\author{
${ }^{1}$ University Hospital "Attikon", Athens, Greece \\ ${ }^{2}$ University of Athens Medical School, University Hospital "Attikon", Athens, Greece \\ ${ }^{3}$ Nursing Department, Technological Educational Institute of Western Greece, Patras, Greece \\ ${ }^{4}$ University of Athens Medical School, University Hospital “Attikon", Athens, Greece \\ ${ }^{5}$ Centers for the Prevention of Addictions and Promoting Psychosocial Health of Municipality of Thessaloniki, \\ Thessaloniki, Greece \\ ${ }^{6}$ Nursing Department, Cyprus University of Technology, Limassol, Cyprus
}

\section{Type of article: Original}

\begin{abstract}
Background: Pancreatic cancer is an aggressive malignancy, and surgical resection is the only therapeutic option with pancreaticoduodenectomy being considered the standard of care. It is essential to take into account the patients' Quality of Life after the resection, in order to make more informed decisions about treatment options. Objective: The aim of the study was to determine perceived Quality of Life levels among patients who undergo pancreaticoduodenectomy, in a period of six months after surgery.

Methods: This prospective study was conducted on all patients $(n=40)$ who underwent pancreaticoduodenectomy in Attikon University General Hospital in Athens, Greece, from January 2013 to June 2015. The Quality of Life was assessed by use of EORTC QLQ-C30 and EORTC QOL-PAN26 questionnaires at four phases: First, after admission at the hospital preoperatively, and then one month, three months, and six months postoperatively. Repeated measurements analysis of variance (ANOVA) was used in order to evaluate changes in Quality of Life measures during the follow-up (postoperative) period. Data analysis was conducted using SPSS version 19. A pvalue of less than or equal to 0.05 was set as the level of significance.

Results: The study revealed a mixed image. Except for the nausea and vomiting scale, where indeed a symptom increase is initially reported and then gradually decreases below preoperative levels by 6 months, scoring in many symptom scales worsens postoperatively. From first to fourth assessment, fatigue (Mean from 23.61 to 38.72 , $\mathrm{p}=0.005$ ) and financial difficulties scoring (Mean from 5.98 to $42.42, \mathrm{p}<0.001$ ) consistently worsen. Functionality scales scoring also tends to get worse between first and fourth assessment, with statistically significant changes for physical $(\mathrm{p}<0.001)$, role $(\mathrm{p}<0.001)$ and social functioning $(\mathrm{p}<0.001)$. However, a slight improvement can be noted in many scales from third to fourth assessment, as in diarrhea (Mean from 32.38 to 29.29), pancreatic pain (Mean from 17.71 to 2.34), global health status (Mean from 50.48 to 52.53) and social functioning (Mean from 43.81 to 48.48 ) scales.

Conclusions: Quality of Life levels among patients who undergo pancreaticoduodenectomy are getting worse following surgery. However, the longitudinal study of these changes may improve patients' postoperative life by formulating evidence-based interventions concerning symptoms treatment and psychological and social support.

Keywords: Pancreatic neoplasms, Pancreaticoduodenectomy, Quality of life
\end{abstract}

\section{Introduction}

Pancreatic cancer is a very aggressive malignancy, with late diagnosis and poor prognosis. The term mainly refers to pancreatic ductal adenocarcinoma, which accounts for more than $90 \%$ of pancreatic tumors (1). It is estimated that

\section{Corresponding author:}

Pavlos Sarafis, Nursing Department, Cyprus University of Technology, Limassol, Cyprus.

Tel: +357.25002586, Email: pavlos.sarafis@cut.ac.cy

Received: April 26, 2017, Accepted: May 10, 2018, Published: July 2018

iThenticate screening: June 04, 2018, English editing: June 04, 2018, Quality control: June 14, 2018

Research project approval: 1516020671 (Thesis number)

Ethics approval: 151602067

(C) 2018 The Authors. This is an open access article under the terms of the Creative Commons Attribution-NonCommercialNoDerivs License, which permits use and distribution in any medium, provided the original work is properly cited, the use is non-commercial and no modifications or adaptations are made. 
pancreatic cancer has an annual incidence of 338,000 cases worldwide, and that it is the cause of 331,000 deaths per year (2). As opposed to other types of cancer, mortality from pancreatic cancer has remained relatively stable in recent years (3), and projections show that it could become the second leading cause of cancer death in the US by 2030 (4). The risk increases with age, as it is usually diagnosed in people older than 70 years old (5). Other risk factors include cigarette smoking, obesity, positive family history, and chronic pancreatitis, amongst others (1). Common symptoms include weakness, weight loss, abdominal pain, back pain, jaundice, nausea, and diarrhea (6). However, early detection remains challenging, as these symptoms usually occur late, and there is no specific screening process or high-risk group (7). As a result, most patients are diagnosed when the cancer has already spread, and this is probably the main cause for its stable mortality and its poor 5-year survival, set at 9.7\% (8). In addition, pancreatic cancer patients score low on validated health-related quality of life (QoL) instruments (9).

Surgical resection is the only therapeutic option for pancreatic cancer (10), and pancreaticoduodenectomy (Whipple's procedure) with regional lymphadenectomy is considered the standard of care (11). At diagnosis, about $15 \%$ of patients have resectable disease (stage I or II), whereas $35 \%$ have locally advanced disease (stage III), and $50 \%$ have metastatic disease (stage IV), which do not allow for curative resection $(12,13)$. For patients with unresectable disease, palliative chemotherapy is the treatment of choice; there is ongoing research regarding whether resection should be considered for some of these patients as well, who fall into the relatively new category of 'borderline resectable' pancreatic cancer (14), and whether some new chemotherapy regimens can render locally advanced pancreatic cancer resectable $(15,16)$. However, in terms of survival, the benefit associated with surgical resection compared with palliative chemotherapy appears very small for certain subgroups of these patients (17), especially the elder ones (18). As for pancreatic cancer survivors, they constitute a relatively understudied population in terms of preferences, barriers, and overall life options after surgery. A recent study on health-related QoL among 16,095 older adult cancer survivors revealed that survivors of multiple myeloma and pancreatic cancer had the poorest scores (19). A recent telephone survey identified future research related to supportive care and QoL of pancreatic cancer survivors as very important to them (20). Therefore, it is essential to also take into account patients' QoL after the resection, in order to make more informed decisions about pancreatic cancer treatment options. Recently, there have been many efforts to map post-operative pancreatic cancer patients' needs and their related QoL. For instance, a Delphi survey among 150 patients diagnosed with pancreatic or periampullary cancer in the Netherlands identified the most important patient-reported outcomes, such as general QoL, fatigue or appetite, to be incorporated in pancreatic cancer care and research (21). A study with semi-structured in-depth interviews of 13 post-operative patients with pancreatic cancer found that appetite problems are common, and that appropriate nutrition support would be helpful (22). Another qualitative study including 12 pancreatic cancer patients and 23 carers revealed that the major QoL-related theme was difficulty in managing gut symptoms and complex dietary issues, indicating the need for expert advice (23). More specifically, delayed gastric emptying has been found to affect significantly post-operative pancreatic cancer patients' QoL (24), while a study of 29 long-term survivors with pancreatic adenocarcinoma who had undergone pancreaticoduodenectomy and were without evidence of disease during at least 3 years of follow-up evaluation revealed complications, such as ascites, which usually manifest more than 3 years after surgery (25). Two other surveys which were conducted recently and entail health-related QoL instruments, showed a considerable decline in QoL in the first days after resection, and improvement of the situation by 60 post-operative days $(26,27)$. Finally, an ongoing randomized controlled trial with 60 post-operative patients is investigating whether intensive physiotherapy improves the QoL of patients after pancreatic resection (28). All these studies contribute to our better understanding of the post-operative QoL of pancreatic cancer patients, and there have been efforts to enhance the care of these patients by making appropriate interventions based on the QoL research findings. The aim of the present study is similar; it is a contribution from Greece where it is attempted to identify key issues related to pancreatic cancer before and after surgical procedure. Given this cancer's poor survival, which unavoidably limits the size of the population available to be studied, it is very important to enrich international literature with more findings to guide the care provided. Additionally, since it is a longitudinal study, it may enrich the knowledge concerning changes of perceived QoL levels through time and contribute in the planning and implementing of adequate medical and psychosocial interventions during different time points, postoperatively.

\section{Material and Methods}

\subsection{Sampling and Population under Study}

The sample of this prospective study consisted of patients who were diagnosed with pancreatic cancer and underwent pancreaticoduodenectomy at Attikon University General Hospital in Athens, Greece, from January 2013 to June 2015. More specifically, during this period 109 patients made an entry to the hospital and they were 
diagnosed with malignant neoplasm of pancreas (Diagnosis Code: ICD10: C25). Forty of the 109 patients underwent pancreaticoduodenectomy. The final sample consisted of these 40 patients.

\subsection{Selection criteria}

The inclusion criteria were: (i) undergoing pancreaticoduodenectomy, (ii) informed consent to participate in the study and (iii) capability to communicate and understand the information that was requested during research procedure. The exclusion criteria were: (i) diagnosis of mental illness and (ii) poor understanding of the Greek language.

\subsection{Instrument}

Quality of life is a subjective notion that needs to be objectified and measured so as to study it and improve it. There are many ways, albeit incomplete, to do so; usually, the appropriate tool is selected depending on the health issue at hand. The European Organization for Research and Treatment of Cancer Quality-of-Life Questionnaire (EORTC QLQ-C30) is a tool developed to assess cancer patients in terms of QoL (29), it has been widely used in many studies, and it has also been validated in the Greek setting $(30,31)$. It consists of two seven-level Likert items on general health and overall QoL, and 28 five-level Likert items on functionality (physical, role, emotional, cognitive and social), symptoms (fatigue, pain, nausea-vomiting, shortness of breath, loss of appetite, sleep disturbances, constipation and diarrhoea), and other aspects of the disease, such as its financial impact. Scores for functional, symptoms and sides effects subscales range from 0 to 100 . The higher score on the functional and global QoL subscales represent the higher level of functioning and global QoL, while the higher score of symptom and side effects subscales represent more severe symptoms and side effects. For some types of cancer, there are also supplementary modules developed by the EORTC. In the case of pancreatic cancer, the EORTC QLQ-C30 is supplemented by the EORTC QOL-PAN26 questionnaire. This tool has also been widely used, and it has been translated and validated in many European countries, including Greece (32). It contains 26 four-level Likert items regarding disease symptoms, treatment side effects and emotional outcomes, all focused on pancreatic cancer. Specifically, it consists of seven subscales: pancreatic pain, upper gastrointestinal symptoms, jaundice, altered bowel habit, health satisfaction, sexuality, and body image. Scores range from 0 to 100. In all cases, higher scores indicate more severe symptoms and worse functioning except the health satisfaction subscale, where higher scores indicate higher health satisfaction levels. Both instruments assess QoL during the past week before the interview. Given their popularity and their relevance, we chose to use the EORTC QLQ-C30 and QOL-PAN26 questionnaires for the purposes of this study. Regarding the reliability of the instrument we used the internal consistency method; the Cronbach's $\alpha$ was $>0.70$ for all scales and subscales of the instruments used.

\subsection{Data collection}

The questionnaires were filled by the researchers according to the responses of the participants, at four phases: first after admission at the hospital preoperatively, and then one month, three months, and six months postoperatively. Responses for the postoperative phases were provided by telephone, unless the patient received chemotherapy at the Attikon hospital, and provided that it was convenient to schedule an appointment there with the researchers at the designated times. Perioperative and early postoperative complications were recorded after the patient's first QoL assessment and subsequent surgery, but before hospital discharge; for reasons of simplicity, we report this data as being part of the first assessment.

\subsection{Data Analysis}

Continuous variables are presented with mean and standard deviation (SD). Qualitative variables are presented with absolute and relative frequencies. Repeated measurements analysis of variance (ANOVA) was used in order to evaluate changes in QoL measures during the follow up (postoperative) period. Bonferroni correction was used in order to control for type I error, in multiple testing. All p-values reported are two-tailed. Statistical significance was

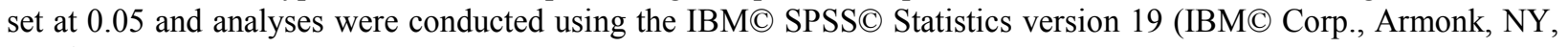
USA).

\subsection{Variables, bias, and potential confounders}

The study aimed to determine perceived QoL levels among patients who undergo pancreaticoduodenectomy in a period of six months after surgery. The independent variables were the sociodemographic characteristics (gender, age, educational level, and marital status), the individual medical history (the presence of a chronic physical or mental disease), and the disease characteristics at the time of the surgical operation. The perioperative and postoperative complications were the mediators. The changes in the QoL domains was the final estimated outcome (presence of pain, role, physical, social, cognitive, emotional and sexual functioning). In order to address potential 
sources of bias, patients informed that they could withdraw from the study at any time without giving explanations and that they could ask any information concerning the study aims and procedure and that the participation was not related in any way with the treatment received.

\subsection{Ethics approval and consent to participate}

The study was conducted according to the ethical principles of the Declaration of Helsinki as revised in Fortaleza in 2013. The researchers received approval for conducting the survey by the Ethics Committee of the University of Athens Medical School (Ref: 151602067), and by the Scientific Council of Attikon University General Hospital (Ref: 388-3/12/2012). The participants were informed that they could withdraw from the study at any time, and the protection of their anonymity was observed at all phases, by use of the appropriate coding.

\section{Results}

The questionnaires were filled, at four phases: first after admission at the hospital preoperatively $(\mathrm{n}=40)$, after one month postoperatively $(n=40)$ where all the patients were eligible to participate, three months postoperatively $(n=39)$ where one patient died, and six months postoperatively $(n=37)$ where two more patient died. Demographics and clinical characteristics of the study sample are presented in Table 1 . The sample consisted of 40 patients $(20$ men and 20 women) with a mean age of 65.6 years ( $\mathrm{SD}=9.4$ years). Most of the participants were married (77.5\%) and $27.5 \%$ were smokers. Also, $77.5 \%$ had a chronic physical disease and $13.2 \%$ had a chronic mental condition. Disease characteristics at the time of the surgical operation (first assessment) are shown in Table 2.

The most common reason for surgery was cancer in the head of the pancreas. With regards to symptoms, $65 \%$ of the respondents had jaundice, $45 \%$ reported pain, $26.3 \%$ diarrhoea and $17.9 \%$ indigestion. None of the patients had metastasis and $95 \%$ had positive nodes. Also, $20 \%$ of the patients had undergone endoscopic retrograde cholangiopancreatography (ERCP). The majority of the patients (95\%) had self-reported changes in their weight status, that is, from diagnosis to admission for surgery, when the first assessment took place (changes in weight status were monitored in more detail postoperatively). Perioperative complications were recorded in $25.6 \%$ of the cases, and early postoperative complications (that is, until hospital discharge) in $25 \%$ of the cases, with the commonest being anastomosis leakage and respiratory failure. Also, it is noted that mean duration of disease (from diagnosis to surgical treatment) was 3.2 months $(\mathrm{SD}=2.7)$, and mean duration of postoperative hospitalization was 11.6 days $(\mathrm{SD}=6.8)$. In total, 3 patients died during the follow-up period. Readmission to hospital was recorded in $35.1 \%$, $29.4 \%$, and $6.1 \%$ of the cases at their second, third, and fourth assessment, respectively. Regarding complications, $10.8 \%$ of the patients reported complications at their second assessment, $5.9 \%$ at their third assessment, and none at the fourth assessment.

Table 1. Patients' demographics and personal history

\begin{tabular}{|c|c|c|}
\hline \multicolumn{2}{|l|}{ Variables } & $\mathrm{n}(\%)$ \\
\hline \multirow[t]{2}{*}{ Sex } & Women & $20(50.0)$ \\
\hline & Men & $20(50.0)$ \\
\hline \multicolumn{2}{|c|}{ Age (year); Mean \pm SD: $65.6 \pm 9.4$} & NA \\
\hline \multirow[t]{7}{*}{ Educational status } & None & $1(2.5)$ \\
\hline & Primary school & $11(27.5)$ \\
\hline & Middle school & $10(25.0)$ \\
\hline & High school & $10(25.0)$ \\
\hline & Technical school & $1(2.5)$ \\
\hline & University & $4(10.0)$ \\
\hline & Postgraduate studies & $3(7.5)$ \\
\hline \multirow[t]{5}{*}{ Family status } & Unmarried & $3(7.5)$ \\
\hline & Married & $31(77.5)$ \\
\hline & Divorced & $5(12.5)$ \\
\hline & Widowed & $1(2.5)$ \\
\hline & Children & $39(97.5)$ \\
\hline \multirow[t]{3}{*}{ Smoking } & No & $18(45.0)$ \\
\hline & Yes & $11(27.5)$ \\
\hline & In the past & $11(27.5)$ \\
\hline \multicolumn{2}{|c|}{ Chronic physical disease } & $31(77.5)$ \\
\hline \multicolumn{2}{|c|}{ Chronic mental disease } & $5(13.2)$ \\
\hline
\end{tabular}


Table 2. Disease characteristics at the time of the surgical operation (first assessment)

\begin{tabular}{|l|l|l|}
\hline Variables & $\mathrm{n}(\%)$ \\
\hline Indication for pancreatoduodenectomy & Cancer in the head of the pancreas & $37(92.5)$ \\
\cline { 2 - 3 } & Cancer of the duodenum & $3(7.5)$ \\
\cline { 2 - 3 } & Cancer of the lower bile duct & $1(2.5)$ \\
\cline { 2 - 3 } & Chronic pancreatitis & $1(2.5)$ \\
\cline { 2 - 3 } & Cancer in the body of the pancreas & $1(2.5)$ \\
\hline \multirow{5}{*}{ Symptoms } & Jaundice & $26(65.0)$ \\
\cline { 2 - 3 } & Indigestion & $7(17.9)$ \\
\cline { 2 - 3 } & Diarrhea & $10(26.3)$ \\
\cline { 2 - 3 } & Pain & $18(45)$ \\
\hline Nodes & & $38(95)$ \\
\hline Metastasis & & $0(0.0)$ \\
\hline Stage & IA & $1(2.5)$ \\
\cline { 2 - 3 } & IB & $4(10.0)$ \\
\cline { 2 - 3 } & IIA & $10(25.0)$ \\
\cline { 2 - 3 } & IIB & $10(25.0)$ \\
\cline { 2 - 3 } & III & $8(20.0)$ \\
\cline { 2 - 3 } & IIIB & $2(5.0)$ \\
\cline { 2 - 3 } & IV & $5(12.5)$ \\
\hline Previous treatment & No & $31(77.5)$ \\
\cline { 2 - 3 } & Radiotherapy & $0(0.0)$ \\
\cline { 2 - 3 } & Chemotherapy & $1(2.5)$ \\
\cline { 2 - 3 } & Both & $0(0.0)$ \\
\hline & ERCP & $8(20)$ \\
\hline Change in weight & & $10(25.0)$ \\
\hline Perioperative complications & & $10(25)$ \\
\hline Postoperative complications (early) & & \\
\hline
\end{tabular}

Changes in QoL domains during the follow up period are presented in Table 3. The EORTC QLQ-C30 items comprise 6 function scales (physical, role, emotional, cognitive, social and global health status/QoL) and 9 symptom scales (fatigue, nausea and vomiting, pain, dyspnea, insomnia, appetite loss, constipation, diarrhoea and financial difficulties). These are presented in Table 3. The QOL-PAN26 items comprise one function scale (satisfaction with health care) and 6 symptom scales (pain, digestive symptoms, altered bowel habit, hepatic, body image and sexuality). These are presented in Table 3. In general, high scoring is desirable for function scales and low scoring is desirable for symptom scales. Scores on global health status, nausea and vomiting, insomnia, dyspnea, emotional functioning, cognitive functioning, and satisfaction with health care domains remained unchanged during the followup period. A significant increase in fatigue scores (Table 3) was found from first to second assessment, as well as from first to fourth assessment overall. Pain had a significant decrease both from first to second assessment, and from first to fourth assessment overall.

Scoring on appetite loss domain increased significantly from first to second assessment, and then remained unchanged (Table 3). Scoring on constipation decreased from first to second assessment, and scoring on diarrhea increased significantly from first to fourth assessment. Financial difficulties increased significantly during the follow-up period. Physical functioning and role functioning scores significantly decreased from first to second assessment, and decreased at a slower rate subsequently (Table 3). Social functioning decreased from first to second assessment, and from second to third assessment. Emotional and cognitive functioning appear relatively unaltered. As for the QOL-PAN26 questionnaire, scoring on pancreatic pain, altered bowel habit, hepatic and sexuality domains decreased from first to second assessment (Table 3). Additionally, scoring on pancreatic pain and sexuality continue to decrease from second to third assessment. Contrarily, digestive symptoms and body image scoring increased during the follow-up period. 
Table 3. Changes in QoL domains during the follow up period

\begin{tabular}{|c|c|c|c|c|c|}
\hline \multirow[t]{2}{*}{ Variables } & \multicolumn{5}{|c|}{$\begin{array}{l}\text { p-values of the changes between separate assessments (Repeated measurements analysis } \\
\text { of ANOVA) }\end{array}$} \\
\hline & $\begin{array}{l}1^{\text {st }} \text { vs. } 2^{\text {nd }} \\
\text { assessment }\end{array}$ & $\begin{array}{l}2^{\text {nd }} \text { vs. } 3^{\text {rd }} \\
\text { assessment }\end{array}$ & $\begin{array}{l}3^{\text {rd }} \text { vs. } 4^{\text {th }} \\
\text { assessment }\end{array}$ & $\begin{array}{l}1^{\text {st }} \text { vs. } 4^{\text {th }} \\
\text { assessment }\end{array}$ & p-value \\
\hline Global health status & 0.130 & 0.320 & 0.553 & 0.117 & 0.089 \\
\hline Fatigue & $0.013 *$ & 0.779 & 0.276 & $0.005^{*}$ & $0.009^{*}$ \\
\hline Nausea and vomiting & 0.608 & 1.000 & 0.513 & 0.899 & 0.912 \\
\hline Pain & $0.018 *$ & 0.196 & 0.213 & $0.025 *$ & $0.017 *$ \\
\hline Dyspnea & 0.325 & 0.160 & 0.325 & 0.374 & 0.110 \\
\hline Insomnia & 0.354 & 0.325 & $0.048^{*}$ & 0.071 & 0.151 \\
\hline Appetite loss & $<0.001^{*}$ & 0.147 & 0.572 & $0.005 *$ & $0.018^{*}$ \\
\hline Constipation & $0.010^{*}$ & 0.160 & 0.325 & $0.002 *$ & $0.001 *$ \\
\hline Diarrhea & 0.264 & 0.147 & 0.521 & $0.037 *$ & $0.012 *$ \\
\hline Financial difficulties & $<0.001 *$ & $0.018 *$ & 0.823 & $<0.001 *$ & $<0.001^{*}$ \\
\hline Physical functioning & $<0.001 *$ & 0.296 & 0.681 & $<0.001 *$ & $<0.001^{*}$ \\
\hline Role functioning & $<0.001 *$ & 0.201 & 0.125 & $<0.001 *$ & $<0.001^{*}$ \\
\hline Emotional functioning & 0.931 & 0.585 & 0.540 & 0.696 & 0.764 \\
\hline Cognitive functioning & 1.000 & 0.557 & 0.876 & 0.768 & 0.661 \\
\hline Social functioning & $<0.001 *$ & $0.020^{*}$ & 0.309 & $<0.001 *$ & \\
\hline Pancreatic pain & $0.012 *$ & $0.045^{*}$ & 0.698 & $<0.001 *$ & $<0.001^{*}$ \\
\hline Digestive symptoms & $0.020 *$ & 0.385 & 0.738 & $0.002 *$ & $0.002 *$ \\
\hline Altered bowel habit & $0.010^{*}$ & 0.839 & 0.090 & 0.147 & $0.003 *$ \\
\hline Liver pain & $<0.001 *$ & 1.000 & 0.184 & $0.003^{*}$ & $0.003^{*}$ \\
\hline Body image & $<0.001 *$ & 0.381 & 0.053 & $<0.001 *$ & $<0.001^{*}$ \\
\hline $\begin{array}{l}\text { Satisfaction with } \\
\text { health care }\end{array}$ & 0.831 & 0.165 & 0.073 & 1.000 & 0.731 \\
\hline Sexuality & $0.010^{*}$ & $<0.001^{*}$ & 0.712 & $<0.001 *$ & $<0.001^{*}$ \\
\hline
\end{tabular}

* Statistically significant at $\alpha \leq 0.05$

\section{Discussion}

These results come to enhance the significance of the study's preliminary findings, which had been published earlier and were based on a patients' sample, half the size of the present one (33). In general, disease characteristics appear similar to those of other relative studies, with jaundice and pain reported as the main symptoms by most respondents (34). The mean length of postoperative hospitalization is notable (11.6 days), as it is very satisfactory compared to reported results of other studies on patients undergoing pancreaticoduodenectomy (16.2 or 17.7 days), depending on whether the pylorus is preserved or not (35). This finding may be attributed to the technique used at the Attikon hospital, which entails the use of a long isolated jejunal loop; this technique is associated with reduced rates of pancreatic leakage, and, therefore, decreased length of stay if other complications do not occur (36).

Previously published studies using the EORTC QLQ-C30 tool suggest that QoL for pancreatic cancer patients undergoing resection decreases in the first few postoperative days (26), and then it increases to achieve full recovery after 6 months (27). Our findings do not follow this trend. Except for the nausea and vomiting scale, where indeed a symptom increase is initially reported and then gradually decreases below preoperative levels by 6 months, scoring in many symptom scales increases (that is, worsens) postoperatively; for instance, fatigue and financial difficulties scoring consistently increase from first to fourth assessment. Functionality scales scoring also tends to get worse (decrease). However, a slight improvement can be noted in many scales from third to fourth assessment, as in diarrhea, global health status and social functioning scales. This could mean that the improvement would continue after the first six follow-up months, for these scales at least. It would be interesting to monitor these scales for a much longer period, as Shaw et al. have done in the past for a median of 42 months postoperatively (37). This is also the case for scales which follow a different pattern; pain and dyspnea tend to improve from first to third assessment, and then worsen from third to fourth assessment. A longer period of follow-up assessment, as well as a larger patient sample, would probably clarify the situation as to whether these are consistent or merely random trends. 
Analysis of the QOL-PAN26 domains also reveals a mixed image. On the one hand, we notice that altered bowel habit and hepatic scoring tend to improve from first to third assessment, as expected judging from previous studies $(38,39)$, but then worsen from third to fourth assessment. Body image scoring consistently increases (worsens) from first to fourth assessment, which is in accordance with what Fitzmaurice et al. report (38). For such a short follow-up period, and considering that the operation (and the changes in body image that it entails) is not a focus area for the PAN-26 tool, this trend is normal. Directly related to body image, sexuality scoring decreases (with a slight increase from $3^{\text {rd }}$ to $4^{\text {th }}$ assessment), which may seem inconsistent with the previous remark; when body image worsens, it is not expected for sexuality to improve. This finding is subject to various interpretations, since pancreatic cancer affects sexuality in many ways. We assume that this domain is also influenced by the surgical operation, an influence which the questionnaires fail to reflect, since they were not originally designed to be used before and after resection. Nonetheless, it is a finding which should be further investigated in future studies.

\section{Study limitations and generalizability}

The study has certain limitations that need to be acknowledged. First, the sample size could be bigger, to increase the generalizability or external validity of the findings. However, as it has already been noted, pancreatic cancer is uncommon, usually non-resectable, and with very poor survival rates. Thus, independent researchers may find it difficult to acquire bigger samples for specific periods of study. A second limitation concerns the follow-up period, which was set at six months. As noted above, a longer period of follow-up assessment would probably clarify some mixed results, such as insomnia, worsening from first to second assessment, improving from second to third, and worsening again from third to fourth assessment, exceeding baseline values. Finally, we already mentioned that the technique used at the Attikon hospital is associated with reduced rates of pancreatic leakage and decreased length of hospital stay (36), which is certainly positive for the patient in terms of QoL; however, if this technique has not been used in similar published studies exploring pancreatic cancer patients' QoL, it constitutes a factor that weakens direct comparison of our study with the others. Therefore, the technique used is a factor that should be carefully explored in future studies assessing QoL before and after pancreaticoduodenectomy.

\section{Conclusions}

As technology improves, it is expected that more cases of pancreatic cancer will be resectable in the near future we have already noted the relatively new category of 'borderline resectable pancreatic cancer, with better results in terms of postoperative QoL. But support for more effective future interventions entails an understanding of the anticipated outcomes. Therefore, in line with other research, we believe that more research initiatives are needed in order to properly evaluate the benefits achieved from pancreaticoduodenectomy to patients diagnosed with resectable pancreatic cancer. Interdepartmental and international collaborations are needed in order to acquire bigger patient samples and longer follow-up periods of monitoring. Pancreatic cancer survivors' QoL is an important aspect of the disease that needs to be studied thoroughly in order to make informed decisions regarding their initial treatment, and to design interventions that will improve their postoperative life.

\section{Acknowledgments:}

The present paper was part of a PhD thesis of the first author, which was conducted at the Faculty of Medicine of the National and Kapodistrian University of Athens (Thesis number: 1516020671). The researchers would like to sincerely thank all the medical and nursing personnel of the $4^{\text {th }}$ surgical clinic of Attikon University General Hospital in Athens and all the patients who participated in the study.

\section{Conflict of Interest:}

There is no conflict of interest to be declared.

Authors' contributions:

All authors contributed to this project and article equally. All authors read and approved the final manuscript.

\section{References:}

1) Muniraj T, Jamidar PA, Aslanian HR. Pancreatic cancer: A comprehensive review and update. Dis Mon. 2013; 59(11): 368-402. doi: 10.1016/j.disamonth.2013.08.001. PMID: 24183261.

2) Ferlay J, Soerjomataram I, Dikshit R, Eser S, Mathers C, Rebelo M, et al. Cancer incidence and mortality worldwide: sources, methods and major patterns in GLOBOCAN 2012. Int J Cancer. 2015; 136(5): E35986. doi: 10.1002/ijc.29210. PMID: 25220842. 
3) Lucas AL, Malvezzi M, Carioli G, Negri E, La Vecchia C, Boffetta P, et al. Global Trends in Pancreatic Cancer Mortality From 1980 Through 2013 and Predictions for 2017. Clin Gastroenterol Hepatol. 2016; 14(10): 1452-62. doi: 10.1016/j.cgh.2016.05.034. PMID: 27266982, PMCID: PMC5028258.

4) Rahib L, Smith BD, Aizenberg R, Rosenzweig AB, Fleshman JM, Matrisian LM. Projecting cancer incidence and deaths to 2030: the unexpected burden of thyroid, liver, and pancreas cancers in the United States. Cancer Res. 2014; 74(11): 2913-21. doi: 10.1158/0008-5472.CAN-14-0155. PMID: 24840647.

5) Siegel R, Naishadham D, Jemal A. Cancer statistics, 2013. CA Cancer J Clin. 2013; 63(1): 11-30. doi: 10.3322/caac.21166. PMID: 23335087.

6) Porta M, Fabregat X, Malats N, Guarner L, Carrato A, de Miguel A, et al. Exocrine pancreatic cancer: symptoms at presentation and their relation to tumour site and stage. Clin Transl Oncol. 2005; 7(5): 189-97. PMID: 15960930.

7) Weledji EP, Enoworock G, Mokake M, Sinju M. How Grim is Pancreatic Cancer? Oncol Rev. 2016; 10(1): 294. doi: 10.4081/oncol.2016.294. PMID: 27471581.

8) Wolfgang CL, Herman JM, Laheru DA, Klein AP, Erdek MA, Fishman EK, et al. Recent progress in pancreatic cancer. CA Cancer J Clin. 2013; 63(5): 318-48. doi: 10.3322/caac.21190. PMID: 23856911.

9) Carrato A, Falcone A, Ducreux M, Valle JW, Parnaby A, Djazouli K, et al. A Systematic Review of the Burden of Pancreatic Cancer in Europe: Real-World Impact on Survival, Quality of Life and Costs. J Gastrointest Cancer. 2015; 46(3): 201-11. doi: 10.1007/s12029-015-9724-1. PMID: 25972062.

10) Wagner M, Redaelli C, Lietz M, Seiler CA, Friess H, Büchler MW. Curative resection is the single most important factor determining outcome in patients with pancreatic adenocarcinoma. Br J Surg. 2004; 91(5): 586-94. doi: 10.1002/bjs.4484. PMID: 15122610.

11) Muniraj T, Barve P. Laparoscopic staging and surgical treatment of pancreatic cancer. N Am J Med Sci. 2013; 5(1): 1-9. doi: 10.4103/1947-2714.106183. PMID: 23378948.

12) Stathis A, Moore MJ. Advanced pancreatic carcinoma: current treatment and future challenges. Nat Rev Clin Oncol. 2010; 7(3): 163-72. doi: 10.1038/nrclinonc.2009.236. PMID: 20101258.

13) Chandrasegaram MD, Goldstein D, Simes J, Gebski V, Kench JG, Gill AJ, et al. Meta-analysis of radical resection rates and margin assessment in pancreatic cancer. Br J Surg. 2015; 102(12): 1459-72. doi: 10.1002/bjs.9892. PMID: 26350029.

14) Lopez NE, Prendergast C, Lowy AM. Borderline resectable pancreatic cancer: definitions and management. World J Gastroenterol. 2014; 20(31): 10740-51. doi: 10.3748/wjg.v20.i31.10740. PMID: 25152577.

15) Suker M, Beumer BR, Sadot E, Marthey L, Faris JE, Mellon EA, et al. FOLFIRINOX for locally advanced pancreatic cancer: a systematic review and patient-level meta-analysis. Lancet Oncol. 2016; 17(6): 801-10. doi: 10.1016/S1470-2045(16)00172-8. PMID: 27160474.

16) Crippa S, Bittoni A, Sebastiani E, Partelli S, Zanon S, Lanese A, et al. Is there a role for surgical resection in patients with pancreatic cancer with liver metastases responding to chemotherapy? Eur J Surg Oncol. 2016; 42(10)1533-9. doi: 10.1016/j.ejso.2016.06.398. PMID: 27423449.

17) Gurusamy KS, Kumar S, Davidson BR, Fusai G. Resection versus other treatments for locally advanced pancreatic cancer. Cochrane Database Syst Rev. 2014; (2): CD010244. doi: 10.1002/14651858.CD010244.pub2. PMID: 24578248.

18) Marmor S, Burke EE, Virnig BA, Jensen EH, Tuttle TM. A comparative analysis of survival outcomes between pancreatectomy and chemotherapy for elderly patients with adenocarcinoma of the pancreas. Cancer. 2016; 122(21): 3378-85. doi: 10.1002/cncr.30199. PMID: 27419382.

19) Kent EE, Ambs A, Mitchell SA, Clauser SB, Smith AW, Hays RD. Health-related quality of life in older adult survivors of selected cancers: data from the SEER-MHOS linkage. Cancer. 2015; 121(5): 758-65. doi: 10.1002/cncr.29119. PMID: 25369293.

20) Arthur AE, Delk A, Demark-Wahnefried W, Christein JD, Contreras C, Posey JA, et al. Pancreatic cancer survivors' preferences, barriers, and facilitators related to physical activity and diet interventions. J Cancer Surviv. 2016; 10(6): 981-89. doi: 10.1007/s11764-016-0544-5. PMID: 27138993.

21) Gerritsen A, Jacobs M, Henselmans I, van Hattum J, Efficace F, Creemers GJ, et al. Developing a core set of patient-reported outcomes in pancreatic cancer: A Delphi survey. Eur J Cancer. 2016; 57: 68-77. doi: 10.1016/j.ejca.2016.01.001. PMID: 26886181.

22) Cooper C, Burden ST, Molassiotis A. An explorative study of the views and experiences of food and weight loss in patients with operable pancreatic cancer perioperatively and following surgical intervention. Support Care Cancer. 2015; 23(4): 1025-33. doi: 10.1007/s00520-014-2455-1. PMID: 25277960. 
23) Gooden HM, White KJ. Pancreatic cancer and supportive care - pancreatic exocrine insufficiency negatively impacts on quality of life. Support Care Cancer. 2013; 21(7): 1835-41. doi: 10.1007/s00520013-1729-3. PMID: 23397095.

24) Eshuis WJ, de Bree K, Sprangers MA, Bennink RJ, van Gulik TM, Busch OR. Gastric emptying and quality of life after pancreatoduodenectomy with retrocolic or antecolic gastroenteric anastomosis. $\mathrm{Br} \mathrm{J}$ Surg. 2015; 102(9): 1123-32. doi: 10.1002/bjs.9812. PMID: 26086157.

25) Chen KT, Devarajan K, Hoffman JP. Morbidity among long-term survivors after pancreatoduodenectomy for pancreatic adenocarcinoma. Ann Surg Oncol. 2015; 22(4): 1185-9. doi: 10.1245/s10434-014-3969-y. PMID: 25384699.

26) Eaton AA, Gonen M, Karanicolas P, Jarnagin WR, D'Angelica MI, DeMatteo R, et al. Health-Related Quality of Life After Pancreatectomy: Results From a Randomized Controlled Trial. Ann Surg Oncol. 2016; 23(7): 2137-45. doi: 10.1245/s10434-015-5077-z. PMID: 26786091.

27) Heerkens HD, Tseng DS, Lips IM, van Santvoort HC, Vriens MR, Hagendoorn J, et al. Health-related quality of life after pancreatic resection for malignancy. $\mathrm{Br} \mathrm{J}$ Surg. 2016; 103(3): 257-66. doi: 10.1002/bjs.10032. PMID: 26785646.

28) Richter S, Uslar V, Tabriz N, Mueser T, Weyhe D. Progressive postresection program (pPRP) after pancreatic resection: study protocol for a randomized controlled trial. Trials. 2016; 17: 74. doi: 10.1186/s13063-016-1200-0. PMID: 26863867.

29) Aaronson NK, Ahmedzai S, Bergman B, Bullinger M, Cull A, Duez NJ, et al. The European Organization for Research and Treatment of Cancer QLQ-C30: a quality-of-life instrument for use in international clinical trials in oncology. J Natl Cancer Inst. 1993; 85(5): 365-76. PMID: 8433390.

30) Kontodimopoulos N, Ntinoulis K, Niakas D. Validity of the Greek EORTC QLQ-C30 and QLQ-BR23 for measuring health-related quality of life in breast cancer patients. Eur J Cancer Care (Engl). 2011; 20(3): 354-61. doi: 10.1111/j.1365-2354.2009.01170.x. PMID: 20345453.

31) Mystakidou K, Tsilika E, Parpa E, Kalaidopoulou O, Smyrniotis V, Vlahos L. The EORTC core quality of life questionnaire (QLQ-C30, version 3.0) in terminally ill cancer patients under palliative care: Validity and reliability in a Hellenic sample. Int J Cancer. 2001; 94(1): 135-39. PMID: 11668488.

32) Fitzsimmons D, Johnson CD, George S, Payne S, Sandberg AA, Bassi C, et al. Development of a disease specific quality of life (QoL) questionnaire module to supplement the EORTC core cancer QoL questionnaire, the QLQ-C30 in patients with pancreatic cancer. Eur J Cancer. 1999; 35(6): 939-41. PMID: 10533475.

33) Arvaniti M, Danias N, Theodosopoulou E, Smyrniotis V, Karaoglou M, Sarafis P. Quality of Life Variables Assessment, Before and After Pancreatoduodenectomy (PD): Prospective Study. Glob J Health Sci. 2015; 8(6): 203-10. doi: 10.5539/gjhs.v8n6p203. PMID: 26755486.

34) Riediger H, Adam U, Fischer E, Keck T, Pfeffer F, Hopt UT, et al. Long-term outcome after resection for chronic pancreatitis in 224 patients. J Gastrointest Surg. 2007; 11(8): 949-59. doi: 10.1007/s11605-0070155-6. PMID: 17534689.

35) Karanicolas PJ, Davies E, Kunz R, Briel M, Koka HP, Payne DM, et al. The pylorus: take it or leave it? Systematic review and meta-analysis of pylorus-preserving versus standard whipple pancreaticoduodenectomy for pancreatic or periampullary cancer. Ann Surg Oncol. 2007; 14(6): 1825-34. doi: 10.1245/s10434-006-9330-3. PMID: 17342566.

36) Fragulidis GP, Arkadopoulos N, Vassiliou I, Marinis A, Theodosopoulos T, Stafyla V, et al. Pancreatic leakage after pancreaticoduodenectomy: the impact of the isolated jejunal loop length and anastomotic technique of the pancreatic stump. Pancreas. 2009; 38(7): e177-82. doi: 10.1097/MPA.0b013e3181b57705. PMID: 19730152.

37) Shaw CM, O'Hanlon DM, McEntee GP. Long-term quality of life following pancreaticoduodenectomy. Hepatogastroenterology. 2005; 52(63): 927-32. PMID: 15966234.

38) Fitzmaurice C, Seiler CM, Büchler MW, Diener MK. Survival, mortality and quality of life after pyloruspreserving or classical Whipple operation. A systematic review with meta-analysis. Chirurg. 2010; 81(5): 454-71. doi: 10.1007/s00104-009-1829-2. PMID: 20020091.

39) Kostro J, Sledziński Z. Quality of life after surgical treatment of pancreatic cancer. Acta Chir Belg. 2008; 108: 679-84. PMID: 19241917. 